\title{
The views of health-care personnel about video consultation prior to implementation in primary health care in rural areas
}

\author{
Annette M. Johansson ${ }^{1}$, Inger Lindberg ${ }^{2}$ and Siv Söderberg ${ }^{3}$ \\ ${ }^{1} \mathrm{PhD}$ student, Division of Nursing, Department of Health Science, Luleå University of Technology, Luleå, Sweden \\ ${ }^{2}$ Assistant Professor, Division of Nursing, Department of Health Science, Luleå University of Technology, Luleå, \\ Sweden \\ ${ }^{3}$ Professor, Division of Nursing, Department of Health Science, Luleå University of Technology, Luleå, Sweden
}

\begin{abstract}
Aim: The aim of this study was to describe the views of health-care personnel about video consultation (VC) prior to implementation in primary health care in rural areas. Background: For people living in rural areas, it is often a long distance to specialist care, and VC could be an opportunity for increased access to care. Therefore, this study was to investigate what views primary health-care personnel had on VC as a working method in the distance between primary and specialist care. The development of technology in society and the introduction of technology in health care mean that the working methods must be adapted to a new approach. It is therefore important that in the initial phase of the introduction of new working methods to capture the personnel views regarding this. Methods: Focus group (FG) discussions with health-care personnel from five primary health-care centres in northern Sweden. The transcribed FG discussions were analysed with qualitative content analysis. Findings: The analysis revealed four main categories: a patient-centred $\mathrm{VC}$; the importance of evaluating costs and resources; new technology in daily work; technology gives new possibilities in future health care.
\end{abstract}

Key words: focus groups; implementation; primary health care; qualitative content analysis; rural areas; video consultation

Received 30 May 2012; revised 7 January 2013; accepted 12 January 2013; first published online 12 February 2013

\section{Introduction}

New technologies as eHealth are currently being used by many health-care professionals and consumers in Europe (Iakovidis et al., 2004). Eysenbach (2001) defined eHealth as an emerging field of medical informatics, public health, and business that offers the means by which health care can be improved via Internet and related technologies. Cashen et al. (2004) described the term eHealth technology as involving such activities as the

Correspondence to: Annette Johansson, PhD student, Division of Nursing, Department of Health Science, Luleå University of Technology, SE-971 87 Luleå, Sweden. Email: annette.johansson@ltu.se electronic exchange of health-related data, voice, or video. Information and communication technology (ICT) is a tool of great importance for the transformation of health care (Augestad and Lindsetmo, 2009; Boman et al., 2009). The use of eHealth technology increases (Adams et al., 2007), and according to Bauer (2002) the digital transformations of health care is a reason for optimism, particularly for people in rural areas. ICT is already a reality in the health-care system, and Bagchi (2006) considers that ICT could be the cheapest and fastest way to bridge the gap between rural and city health-care practice. Further, Bauer (2002) stated that access to healthcare service will be defined less in terms of personnel and local medical facilities and more in

(C) Cambridge University Press (2013). The online version of this article is published within an Open Access environment subject to the conditions of the Creative Commons Attribution-NonCommercial-ShareAlike licence <http://creativecommons.org/ licenses/by-nc-sa/3.0/>. The written permission of Cambridge University Press must be obtained for commercial re-use. 
terms of fast functioning communication links to the network of 'wired' practitioner. Studies (Augestadt and Lindsetmo, 2009; Hanson et al., 2009) suggest that ICT is one of the solutions for future problems of access to health care, quality, and costs.

The use of video consultation (VC) in health care was evaluated as having a positive impact on reducing the number of hospital admissions and improving the quality of care (Abrahamian et al., 2002). VCs increase the possibility for just in time diagnosis' from specialist when there is no waiting time for visit by referral. It has been used in different settings and contexts in health care, for example, ophthalmology (Bergua et al., 2009), endocrinology/diabetes management (Nikkanen et al., 2008), cardiology (Boman et al., 2009), dermatology (Edison et al., 2011), and in psychiatry (Stain et al., 2011). Another example is when a patient asks for a second opinion from another specialist physician (Törnqvist et al., 2000; Visser et al., 2010). According to Mair and Whitten (2000), the presence of the general practitioner (GP), patient, and specialist physician at the same time in $\mathrm{VC}$ are considered superior to consultation via telephone as it permitted direct communication. Lundvoll and Nilsen (2008) describe that the use of VC in healthcare organizations is becoming more and more common and that VC gives opportunities for collaborative decision making between different levels of health care. Grealish et al. (2005) found that patients experience $\mathrm{VC}$ at least as private and effective as in a physical face-to-face meeting.

Studies (Lindberg et al., 2007; Taylor, 2008; Lindberg et al., 2009) have shown that VC increased the opportunities to accessibility to relevant expertise. It also offers great opportunities to disseminate and receive medical knowledge for GPs from the specialist physician (Lundvoll and Nilsen, 2008; Ignatius et al., 2010). Donnem et al. (2011) have shown that VC is a useful tool to offer high-quality care when a GP and a specialist physician collaborate. Further, Augestadt and Lindsetmo (2009) described VC as a clinical tool, and it offers patients expertise in treatment at long distance.

When introducing ICT in health-care organizations, it is important that the users will have positive experiences to avoid disappointment with the efficiency and efficacy of the method (Klein et al., 2005; Hanson et al., 2009). Problems with the technology are reported often due to inexperience (Ignatius et al., 2010) or poor picture and sound quality (Careau et al., 2008; Varkey et al., 2008). Studies (Careau et al., 2008; Varkey et al., 2008) show that the quality of the techniques such as picture, lighting, and sound is important in order to offer a firm diagnosis (Groth et al., 2008). With improved picture quality (Careau et al., 2008) and increased experience of the technology and its use, the specialist physician could become more skilled in assessing when a diagnosis is possible to set.

When implementing new methods in an organization it requires changes in responsibilities and duties. Therefore, it is important that the changes in workload are evaluated (Brebner et al., 2005). According to Joseph et al. (2011), staff expressed scepticism about ICT and worries about the potential increased workload. Barry et al. (2003) stated that technical problems can arise and it is time consuming to have IT staff involved all the time. The lack of technical support was a significant problem for rural areas (King et al., 2007). Joseph et al. (2011) described that there were also difficulties in gaining access to computers for staff involved in telehealth. According to Brebner et al. (2005), protocols for use of technology were poor or non-existent. In addition, there was lack of training because the requirement for training often was underestimated.

In today's society, communication technology, in all forms, is common and according to Orruño et al. (2011) it is often in health care seen as an effective way to increase access to care. A key factor when implementing new technology in health care is the health-care providers' acceptance of the alteration, as there are both positive and negative perceptions about using VC. Therefore, it is important to have knowledge regarding the health-care staffs' views of implementing the technology before the starting point to contribute to approaches to implementation in primary health care. Projects with new working methods and techniques have been tested, but often no implementation has occurred after the project ended. Therefore, we believe that investigating the views of the health-care personnel before the technology is tested is important and will facilitate the implementation of VC. Moreover, this approach provides the opportunity to support staff in the implementation of this new approach and technique. 


\section{Aim of the study}

The aim of this study was to describe health-care personnel's views on VC before implementing the technology in their work.

\section{Method}

An inductive qualitative design was used in this study because the aim was to describe the views of health professionals on VC before using the technology. According to Elo and Kyngäs (2008), inductive content analysis can be used in situations with insufficient former knowledge about the phenomenon. With inductive content analysis, the researcher arrives at a result through the interpretation of data ranging from the specific to the general; as such, particular instances are observed and then combined into a larger whole or general statement. Focus group (FG) discussions (cf. Krueger and Casey, 2009) were used for data collection because the method works particularly well when the researcher wants to understand the participants' impressions, opinions, and feelings around a specific topic. The FG offers participants a more natural environment than that of an individual interview because participants can influence and are influenced by one another, which is quite similar to the dynamics of real-life situations.

\section{Context}

This study was performed in the northern part of Sweden at five different health-care centres. The health-care centres were situated in rural areas. The range to the nearest hospital was about $128 \mathrm{~km}$. The county of Norrbotten covers a quarter of Sweden and is the largest county in terms of land surface. The county has $<250000$ inhabitants, which is $2.8 \%$ of the entire Swedish population. The inland is sparsely populated, whereas most of the inhabitants in the county of Norrbotten live within a few miles from the largest city in the county; the central hospital is situated close to the largest city (Central Statistics Office Sweden, 2007). This study has been conducted based on the County Council of Norrbotten plans to introduce VC in some medical specialities. The technology planned for use is a desktop speaker, microphone, a Logitech Webcam, and
Polycom $\mathrm{CMA}^{\mathrm{TM}}$ desktop PC-based video and chat program.

\section{Participant and procedure}

A purposive sample of 19 (17 women and two men) health-care personnel participated in the study. A majority of the participants were women as this is representative of the personnel populations in the health-care centres included in the study. According to Krueger and Casey (2009), FGs can be homogeneous but should include sufficient variation in opinions when the participants have something in common with the area of interest to the researcher (ie, in this case healthcare personnel's views on VC before implementing the technology). The participants were registered nurses $(n=2)$, district nurses (DN; $n=9)$, midwifes $(n=2)$, managers of the healthcare unit $(n=2)$, biomedical analysts $(n=1)$, and physicians $(n=3)$. They were aged between 30 and 64 years $(\mathrm{md}=48)$ and had been working in the health-care sector between 5 and 45 years $(\mathrm{md}=24)$. The managers at each primary healthcare centre were informed about the study and asked for their approval. Information about the object of the study was given both verbally and in writing to the health-care staff. The inclusions criteria for participation were: experience of working more than one year in the primary health care and no previous experience of working with VC.

\section{Data collection}

Data were collected through FG discussion during 2010. In total five FG discussions were performed, two groups with three participants, two groups with four participants, and one group with five participants (Table 1).

Table 1 FG design

\begin{tabular}{|c|c|c|c|c|c|}
\hline Profession & FG 1 & FG 2 & FG 3 & FG 4 & FG 5 \\
\hline Registered nurse & & & 1 & & 1 \\
\hline DN & 2 & 1 & 1 & 2 & 3 \\
\hline Midwife & 1 & 1 & & & \\
\hline Physicians & & & 2 & 1 & \\
\hline $\begin{array}{l}\text { Manager of the health } \\
\text { care unit }\end{array}$ & & 1 & 1 & & \\
\hline Biomedical analysts & 1 & & & & \\
\hline Participants & 4 & 3 & 5 & 3 & 4 \\
\hline
\end{tabular}

$\mathrm{FG}=$ focus group; $\mathrm{DN}=$ district nurse. 
According to Kitzinger and Barbour (1999), even as few as three participants are enough for a FG discussion. The variation of professionals in the FGs gave abundant variations in views on the implementation of the new working method. The moderator is responsible to allocate the word so everyone get the opportunity to make their voice heard (Krueger and Casey, 2009). The size of the FGs was relatively small but it was not a problem in this study because the participants were verbal and did not have problem with having a different opinion than the others in the group. Another advantage of relatively small groups was that everyone could be heard (cf. Kitzinger and Barbour, 1999; Krueger and Casey, 2009). The FG discussions were conducted in a quiet room in the primary health-care centres and were guided by open-ended questions. The first author organized and was the moderator of the FG. The moderator's role is to facilitate the discussion in a non-directive way using predetermined questions (Gibson and Bamford, 2001). The following thematic areas were used in the FG discussions: possibility and consequences when having specialized VC, significance of work and impact on the organization related to VC, the patients' situation when using VC. Participants discussed the thematic areas and answered follow-up questions that were asked in order to get a broad and informative picture of the participants' views on the subject. The second author participated as an observer and took notes for follow-up questions (cf. Krueger and Casey, 2009). The advantage of having an observer supporting the moderator was that the volume of information gathered rose and it strengthened the validity of the study. Each FG discussion lasted between 35 and 60 min $($ mean $=45)$ and were recorded on an audio storage device and later transcribed verbatim.

\section{Data analysis}

The FG discussions were analysed with a qualitative content analysis. Content analysis methodology provides a systematic and objective way to make meaningful conclusions to describe a specific phenomenon of verbal communication, visual, or written data (cf. Downe-Wamboldt, 1992). The analysis started with reading the interview text several times in order to gain a sense of the content. Units of analysis, includes words, sentences, phrases, paragraphs, or whole text that corresponded with the aim of the study were identified and were given a code. The identified unit of analysis were condensed and sorted into categories based on similarities and difference in content. Categories were then subsumed into four final categories. Once the final categories were determined, the units of analysis were reread and checked for the appropriateness of their categorization. The authors checked the analysis independently. The findings were then discussed to reach a final agreement.

\section{Ethics}

The managers for the primary health-care centres gave their permission for the study to be performed. The participants were informed about the study and were reassured that their participation was voluntary. They were guaranteed confidentiality and an anonymous presentation of the results. Informed consent was given by the participants. The study was approved by the Regional Ethical Board, Sweden (dnr. 2010-5-31).

\section{Results}

The analysis resulted in four categories: a patientcentred VC, saving time and money, new technologies in daily work and technologies in the future. The categories are presented below and illustrated by quotes from the participants.

\section{A patient-centred $\mathrm{VC}$}

Participants described the importance that the VC should be patient centred. They said that although VC was an advantage for the patients as it could save them travel time; at the same time it could be a disadvantage not to have physical face-to-face meetings. Therefore, they said that it was important when having a VC that the specialist physician at the specialist clinic could talk directly to the patient and not only to the GP. Participants described that VC may seem very technical. Therefore, information that may be relevant to the patients care could get lost without personal contact and for them it was the patient's decision to participate in a VC. They said that it was important when VC should be implemented in health care that the first meeting should be in person. This was in some 
way in contrast with the GP that said they did not find it necessary:

One may consult with the patient before [the VC] to figure out and write down what you think is important and what you want to have answer to in order to help and bring the consultation to be patient-centred. Because it can be so ... here we are two specialists [DN and GP] and we have knowledge of this technology [VC] so the patient can experience themselves very exposed

(FG 1)

Participants emphasized that it was important for the patients to feel safe when participating in a VC. They said that a prerequisite for assuring patient safety during the VC was that the staffs have to be comfortable with the technology. Participants said that it might be difficult for the patient to discuss sensitive issues in a VC. DN said that VC with a patient probably would be better than a telephone call, as they considered it likely that the patient was more honest in a face-to-face VC.

It's not fun if you in front of the patient appear to have lack of knowledge about the technology when you shall try it. It's clear that you should be able to handle the stuff I think ... If I'm not sure then the patient experiencing that ... but do the staff not know what they are doing? [...] it can lead to suspicions or concerns or insecurity [for the patient]

(FG 5)

District nurses said that when a specialist physician talking about, for example, treatment compliance with a patient face to face via VC, DNs considered that a nurse must be present. They meant that the physicians sometimes used a language that could be difficult for the patients to understand. The DNs thought that if they were present they could explain the information for the patients.

$\mathrm{Mm}$, they [the physicians] can of course use a language that can be a bit difficult to understand for the patient. If you aren't informed and you don't think about it [...]. I think of technical terms and Latin terminology and, that the patient can think: but what is that it sounded dangerous...

(FG 1)
District nurses expressed wishes about being able to consult the GP via VC when they were on home visit to a patient. Having that possibility, they could avoid unnecessary travels to the primary health-care centre both for the patient and themselves. It could also reduce the time when a patient was in need for an urgent medication such as antibiotics or analgesic.

\section{The importance of evaluating costs and resources}

Participants described the importance of evaluating costs and personnel resources when implementing new methods. They said that it was a good idea to use VC in their work, both for the patients and themselves. It was a cost investment of the equipment, but it was a small cost in relation to decreased travel costs, less long exhausting journeys for the patient, and the environmental impact. When discussing prerequisites for $\mathrm{VC}$ to work, the participants expressed that no major organizational changes has to be made.

Much is a planning issue... because you are with the patient anyway, somewhere he or she is coming to you again. So if you take it now or if you take it in two weeks, it's up to you

(FG 3)

Participants stated that the cost for the equipment and personnel resources as well as organizing and developing VC was the county council's responsibility. Participants said that it would be cheaper if the consultant specialist physician came to the primary health-care centre for physical face-toface consultations with the patient.

It's clear that it saves a lot of time and of course it saves a lot of money for the county council. But it takes resources from the health care centre and this of course is not compensated

(FG 4)

There was also an opinion that organizing and performing $\mathrm{VC}$ was likely to require so much time that they rather would order transport for the patient to the specialist physician at the hospital. Participants also claimed that they could not see any use for VC with patients as transfer of information could occur in other ways such as telephone.

We've terribly many older people, terribly many who are sick. They will either come 
here [to the primary health care centre] or we go to their home. Instead of cancelling those visits... I rather send them [the patients in need of $\mathrm{VC}$ ] to a specialist physician even if it's a long travel

(FG 2)

But there were also participants who said that it was a good idea to use VC in their work, both for the patients and themselves. The DNs said that they could make home visits to patients instead of being an assistant when the GP and patient were having a $\mathrm{VC}$ with the specialist physician. In order to save time, participants considered that if new technology should be implemented, it was important that it was carefully scheduled for all participants involved in the VC. Participants requested resources in terms of a special equipped room where the $\mathrm{VC}$ could take place. There were ideas from the participants about portable devices or equipment, which would make it easier to find time place for VC.

\section{New technology in daily work}

Participants also expressed aversion towards new working methods, including technology, as they often had to deal with technology that did not work properly and they did not consider it to be their job to fix it. There were also expressions from participants who felt that they would have to perform tasks that were not part of their profession or that they were trained for.

In our County Council we should be so skilled and manage everything by our self. I mean, how many nursing hours have we spent among the wires and that was not quite what you wanted to become - a 'cord nurse'

Participants said that it was essential and a prerequisite for the usability that the technology was tested, problems solved, and that it would be user-friendly both for themselves and for their patients. They meant that possible obstacles with VC were such limitations as bad sound and picture quality. Participants stressed the importance to have technical support available.

The more technology ... the more sources of error as well [...] you start [the computer and the program] and it will not work [...] someone need to check the technology and there must be someone who does. We can see that with all other equipment, the more we have, the worse is the functional controls on them and the management of it

(FG5)

Participants said that the technology that will be used in the VC was not something they had knowledge about. District nurses described a scenario where they had to take responsibility managing the actual equipment as well as the VC. Several of the participants expressed that they did not have any problems handling technology such as computers, microphones, and cameras. The age of the DNs and GPs was considered to be of no significance for the willingness and ability to use new technologies.

District nurses were fully scheduled with meeting patients and therefore did not want to be involved in VC with a specialist physician. They meant that the GP could refer the patient to the specialist physician at the hospital. GPs pointed out that they most often had long experience and consulted each other and therefore had no need of a VC with a specialist physician. They also expressed that if the specialist physicians were far away from the primary health-care centre they could be forced to use VC.

\section{Technology gives new possibilities in future health care}

Participants described different ideas about possibilities the technology could bring about in the future. They had ideas about treatment series for psychologists, second opinions, follow-up meetings of medical treatment, and VCs concerning dermatology or nutrition problems. They also had ideas about VCs with allergy nurses, speech therapists, endocrinologists, and for people with several illnesses that have been discharged from the hospital. Participants also had ideas about what would be possible in the future with VC from the patients' home. They discussed that many people have computers with web cameras in their homes and thereby it gave opportunities for the patients to book time for a visit by themselves. They thought that when it becomes natural to see the face of the other person in the phone it would help us develop along with the technology:

If I automatically can see you and you can see me on a screen, it's given to see the 
other person [when talking over distance] then it probably becomes natural for us. But we cannot use it [VC] with a patient if we don't believe in it ourselves ...

Participants had ideas that education and tutorial by the specialist physician or specialist nurse via video to GPs or DNs were considered as a good idea. GPs, however, said that there were some assessments that could only be done via physical face-to-face contact. They considered that it was not possible to educate colleagues through VC. They meant that if there were questions concerning a diagnosis or treatment, it was important to have the possibility to do a physical examination:

It's we [GPs] who supervise and teach the intern physicians ... when working with surgery the intern physician have to have someone beside with knowledge... I don't think it would be successful if someone from the video [VC] say do this do that if they can't feel with their hands like the GP who teaches the internal physician: I feel like this and if you touch what do you feel ... do you understand this

(FG 3)

Participants emphasized that there were some specialist areas that not fit for VC; they mentioned ophthalmology, otology, and proctology as examples.

\section{Discussion}

The results show that the participants had concerns that VC should not be patient centred. They considered it a risk that the patient would be a passive participant instead of in the centre and that the discussion should be between the GP and the specialist physician. A consequence could be that the patients do not want to participate in a VC meeting. A result of that could be missed benefits and advantages for both patients and health-care provider. In order to create a patientcentred care, the conversation must be between the specialist physician and the patient, not between the specialist physician and the GP if not necessarily for clarifying issues. According to Agha et al. (2009), the patient undertakes a more passive role today as it is the physician who controls the dialogue. Qidwai et al. (2008) stated that ICT, this includes patient-physician communication, can serve as a tool for improving primary health care. Further, the ICT gives the patient opportunity to be more involved in their care, but can also give greater expectations on care from the patients' view. The parties involved in $\mathrm{VC}$ can be seen as the beneficiary of the result of this study. GPs will have the opportunity to be trained by specialist colleagues, patients will receive specialist help without long waiting time, and specialist clinic will hopefully reduce the number of referrals (cf. Abrahamian et al., 2002; Lundvoll and Nilsen, 2008; Augestadt and Lindsetmo, 2009).

In this study, DNs pointed out a fear that they could be forced to participate in the VC, because the GPs sometimes use language that is difficult for the patient to understand. de Veer et al. (2011) described that when health-care personnel thought that patients would benefit from the technology, they had a more positive attitude towards it. Although the results show that the participants thought that it was a good idea to use $\mathrm{VC}$, they pointed out the importance to evaluate costs and personnel resources when implementing new methods. This is in line with Qidwai et al. (2008), who stated that when implementing ICT it is essential to have concerns about time and costs. In this study, the health-care personnel estimated that the costs for the equipment ought to be small compared with the benefits and savings. Benefits that the health-care personnel emphasized were less travel costs, less long exhausting journeys for patients, and less environmental impact. Smith et al. (2007) demonstrate a clear benefit of using VC, although there are costs for equipment, the profit is large savings in patient travel and accommodation. Schaafsma et al. (2007) described that VC affects patient care directly with the increased availability to medical facilities and indirectly through education of health-care professionals. Another advantage with VC is that the patient does not need to be called for follow-ups, and it is also positive that the GP can hear and discuss the specialist physicians' treatment advice right away.

The results show that there is some aversion towards new working methods, including technology. Participants have the experience that the technology often does not work properly and when it happens they have to solve the problem themselves even though that it is not their job. Jarvis-Selinger et al. (2008) describe that to 
accomplish sustainable use of ICT, it requires considerable groundwork among staff to ensure confidence regarding its utility. According to Broens et al. (2007), there must be a reliable system and supporting infrastructure. The result of poor technical feasibility often ends in distrust and low levels of satisfaction.

Several participants said that they did not have any problem handling technology. One reason for this can be a more positive view to try new methods involving technology. Brebner et al. (2005) describes that in order to be successful in working with $\mathrm{VC}$, it must be used regularly to maintain the skills of the users. It is of great importance for participants that they can trust the technology in order to feel secure. This study shows that the health-care personnel's views were that VC could benefit collaboration between the GP and specialist physician, and that specialist physician would be more accessible. According to Morténius et al. (2012), there is a greater willingness for changes for those who have fewer years in primary health care. Employees who have a positive attitude towards organizational change are also more likely to change their attitude and their working methods. Venkatesh et al. (2000) stated that, although the interest in technology among men often applies technology itself, female interest tends to steer to the use of technology. Further, they stated what for men often are a goal in itself is a tool for women. According to Finlayson et al. (2012), it is important that those in the front line, who are responsible for implementing new parts in the workplace, are in favour of the policy intentions. Further, they describe that to ensure that the objectives of a policy are realized, it is important that those responsible for the implementation have a positive attitude.

The results show that the participants have many ideas about new technology and its possibilities. Qidwai et al. (2008) describes that as ICT becomes cheaper, more accessible, and easier to use, so does the potential for ICT between patient and doctor. The result in this study also shows that even if the attitudes are positive to implementing $\mathrm{VC}$ as a new working method, there are strong opinions that it does not fit all diagnoses or patients.

\section{Conclusion}

This study demonstrates that the participants identified many advantages for using VC for consultation if it functions well. They emphasized the importance of a well-functioning training and technical support team before the implementation of VC. Further, the results show that the health-care personnel stressed that using $\mathrm{VC}$ for consultations should be evaluated with regard to both materials and personal resources. Additionally, the health-care personnel indicated that the consultation should be patient centred; otherwise, they thought that the patient might resist using the method when meeting with their specialist physician.

\section{Acknowledgements}

The authors are grateful to the participants in the study. The study was supported by the Department of Health Science and e-Health Innovation Centre (EIC) at Luleå University of Technology, Luleå, Sweden.

\section{References}

Abrahamian, H., Schuller, A., Mauler, H., Prager, R. and Irsiger, K. 2002: Transfer of knowledge from the specialist to the generalist by videoconferencing: effect on diabetes care. Journal of Telemedicine and Telecare 8, 350-55.

Adams, A., Adams, R., Thorogood, M. and Buckingham, C. 2007: Barriers to the use of e-health technology in nurse practitioner-patient consultation. Informatics in Primary Care 15, 103-09.

Agha, Z., Roter, D.L. and Schapira, R. 2009: An evaluation of patient-physician communication style during telemedicine consultations. Journal of Medical Internet Research 11, e36.

Augestad, K.M. and Lindsetmo, R.O. 2009: Overcoming distance: video-conferencing as a clinical and educational tool among surgeons. World Journal of Surgery 33, 1356-65.

Bagchi, S. 2006: Telemedicine in rural India. PLoS Medicine 3, e82.

Barry, N., Campbell, P., Reed, N., Reid, M.E., Bower, D.J., Norrie, J. and Currie, G.D. 2003: Implementation of videoconferencing to support a managed clinical network in Scotland: lessons learned during the first 18 months. Journal of Telemedicine and Telecare 9, Suppl 2, 7-9.

Bauer, J. 2002: Rural America and the digital transformation of health care. New perspective on the future. The Journal of Legal Medicine 23, 73-83.

Bergua, A., Mardin, Y.C. and Horn, F.K. 2009: Teletransmission of stereoscopic images of the optic nerve head in glaucoma via internet. Telemedicine and e-Health 15, 439-44. 
Boman, K., Olofsson, M., Forsberg, J. and Boström, S-Å. 2009: Remote-controlled robotic arm for real-time echocardiography: the diagnostic future for patients in rural areas. Telemedicine and e-Health 15, 142-47.

Brebner, J.A., Brebner, E.M. and Ruddick-Bracken, H. 2005: Experience-based guidelines for the implementation of telemedicine services. Journal of Telemedicine and Telecare 11, Suppl 1, 3-5.

Broens, T., Huisin'tVeld, R., Vollenbroek-Hutten, M., Hermens, H., van Halteren, A. and Nieuwenhuis, L. 2007: Determinants of successful telemedicine implementations: a literature study. Journal of Telemedicine and Telecare 13, 303-09.

Careau, E., Vincent, C. and Noreau, L. 2008: Assessing interprofessional teamwork in a videoconference-based telerehabilitation setting. Journal of Telemedicine and Telecare 14, 427-34.

Cashen, M.S., Dykes, P. and Gerber, B. 2004: E-health technology and internet resources, barriers for vulnerable populations. Journal of Cardiovascular Nursing 19, 209-14.

Central Statistics Office Sweden. 2007: Demografisk rapport (Demographic report), 1.

de Veer, A.J.E., Fleuren, M.A.H., Bekkerna, N. and Francke, A.L. 2011: Successful implementation of new technologies in nursing care: a questionnaire survey of nurse-users. BMC Medical Informatics and Decision Making 11, 67.

Downe-Wamboldt, B. 1992: Content analysis: method, applications and issues. Health Care for Women International 13, 313-21.

Donnem, T., Ervik, B., Magnuissen, K., Andersen, S., Pastow, D., Andreassen, S., Norstad, T., Bremnes, R.M. and Nordoy, T. 2011: Bridging the distance: a prospective tele-oncology study in Northern Norway. Support Care Cancer, doi:10.1007/s00520-011-1319-1.

Edison, K., Chance, L., Martin, K., Braudis, K. and Whitted, M.D. 2011: Users and nonusers of university-based dermatology services following a teledermatology encounter: a retrospective descriptive analysis. Telemedicine and e-Health 17, 1-5.

Elo, S. and Kyngäs, H. 2008: The qualitative content analysis process. Journal of Advanced Nursing 62, 107-15.

Eysenbach, G. 2001: What is e-health? [editorial]. Journal of Medical Internet Research 3, e20. doi:10.2196/jmir.3.2.e20.

Finlayson, M.P., Sheridan, N.F., Cumming, J.M. and Fowler, S. 2012: The impact of funding changes on the implementation of primary health care policy. Primary Health Care Research \& Development 13, 120-29.

Gibson, F. and Bamford, O. 2001: Focus group interviews to examine the role and development of clinical nurse specialist. Journal of Nursing Management 9, 331-42.

Grealish, A., Hunter, A., Glaze, R. and Potter, L. 2005: Telemedicine in a child and adolescent mental health service: participants' acceptance and utilization. Journal of Telemedicine and Telecare 11, Suppl 1, 53-55.

Groth, K., Olin, K., Gran, O. and Permert, J. 2008: The role of technology in video-mediated consensus meetings. Journal of Telemedicine and Telecare 14, 349-53.

Primary Health Care Research \& Development 2014; 15: 170-179
Hanson, D., Calhoun, J. and Smith, D. 2009: Changes in provider attitudes toward telemedicine. Telemedicine and e-Health 15, 39-43.

Iakovidis, I., Wilson, P. and Healy, J.C. 2004: E-health: current situation and examples of implemented and beneficial e-health applications. Amsterdam, Oxford: IOS Press.

Ignatius, E., Perälä, S. and Mäkälä, K. 2010: Use of videoconferencing for consultation in dental prosthetics and oral rehabilitation. Journal of Telemedicine and Telecare 16, 467-70.

Jarvis-Selinger, S., Chan, E., Payne, R., Plohman, K. and Kendall, H. 2008: Clinical telehealth across the disciplines: lesson learned. Telemedicine and e-Health 14, 720-25.

Joseph, V., West, R.M., Schickle, D., Keen, J. and Clamp, S. 2011: Key challenges in the development and implementation of telehealth projects. Journal of Telemedicine and Telecare 17, 71-77.

King, G., Richards, H. and Godden, D. 2007: Adoption of telemedicine in Scottish remote and rural general practices: a qualitative study. Journal of Telemedicine and Telecare 13, 382-86.

Kitzinger, J. and Barbour, R.S. 1999: Introduction: the challenge and promise of focus groups. In Babour, R.S. and Kitzinger, J., editors, Developing focus groups research. London: SAGE Publications Limited, pp. 7-9.

Klein, D., Davis, P. and Hickey, L. 2005: Videoconferences for rural physicians' continuing health education. Journal of Telemedicine and Telecare 11, Suppl 1, 97-99.

Krueger, R.A. and Casey, M-A. 2009: Focus groups - a practical guide for applied research, fourth edition. Thousand Oaks, California: SAGE Publications.

Lindberg, B., Axelsson, K. and Öhrling, K. 2009: Taking care of the baby at home but with nursing staff as support: the use of videoconferencing in providing neonatal support to parents of preterm infants. Journal of Neonatal Nursing 15, $47-55$.

Lindberg, I., Öhrling, K. and Christensson, K. 2007: Midwives' experience of using videoconferencing to support parents who were discharged early after childbirth. Journal of Telemedicine and Telecare 13, 202-05.

Lundvoll, L. and Nilsen, A. 2008: Teleconsultation collaborative work and opportunities for learning across organizational boundaries. Journal of Telemedicine and Telecare 14, 377-80.

Mair, F. and Whitten, P. 2000: Systematic review of studies of patient satisfaction with telemedicine. British Medical Journal 320, 1517-20.

Morténius, H., Fridlund, B., Marklund, B., Palm, L. and Baigi, A. 2012: Utilization of strategic communication to create willingness to change work practices among primary care staff: a long-term follow-up study. Primary Health Care Research \& Development 13, 130-41.

Nikkanen, T., Timonen, M., Ylitalo, K., Timonen, O., Keinänen-Kiukaanniemi, S. and Rajala, U. 2008: Quality of diabetes care among patients managed by teleconsultation. Journal of Telemedicine and Telecare 14, 295-99. 
Qidwai, W., Beasley, J.W. and Gomez-Clavelina, G. 2008: The present status and future role of family doctors: a perspective from the international Federation of Primary Care Research Network. Primary Health Care research \& Development 9, 172-82.

Orruño, E., Gagnon, M.P., Asua, J. and Abdeljelil, A.B. 2011: Evaluation of teledermatology adoption by health-care professionals using a modified Technology Acceptance Model. Journal of Telemedicine and Telecare 17, 303-07.

Schaafsma, J., Pantazi, S.V., Moehr, J.R., Anglin, C. and Grimm, N.A. 2007: An economic evaluation of a telehealth network in British Columbia. Journal of Telemedicine and Telecare 13, 251-56.

Smith, A.C., Scuffham, P. and Wotton, R. 2007: The costs and potential of a novel telepaediatric service in Queensland. BioMed Central Health Service Research 7, 35.

Stain, H.J., Payne, K., Thienel, R., Michie, P., Carr, V. and Kelly, B. 2011: The feasibility of videoconferencing for neuropsychological assessments of rural youth experiencing early psychosis. Journal of Telemedicine and Telecare 17, 328-31.

Taylor, R. 2008: Use of the internet to optimise collaborative healthcare research. Nursing Standard 22, 35-38.

Törnqvist, H., Holm-Sjögren, L. and Schweiler, А․ 2000: Telemedicin - regional och nationell samverkan. Stockholm: Landstingsförbundet.

Varkey, P., Schumacher, K., Swanton, C., Timm, B. and Hagen, P.T. 2008: Telemedicine in the work site: a study of feasibility, and patient and provider satisfaction. Journal of Telemedicine and Telecare 14, 322-25.

Venkatesh, V., Smith, R.H. and Morris, M. 2000: Why don't men ever stop to ask for directions? Gender, social influence, and their role in technology acceptance and usage behaviour. MIS Quarterly 24, 115-39.

Visser, J.J.W., Bloo, J.K.C., Grobbe, F.A. and VollenbroekHutten, M.M.R. 2010: Video teleconsultation service: who is needed to do what, to get it implemented in daily care? Telemedicine and e-Health 16, 439-45. 